\title{
Effect of bleaching agents containing fluoride or calcium on enamel microhardness, roughness and permeability
}

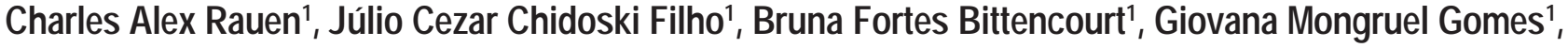 \\ João Carlos Gomes ${ }^{1}$, Osnara Maria Mongruel Gomes ${ }^{1}$
}

${ }^{1}$ Universidade Estadual de Ponta Grossa - UEPG, School of Dentistry, Area of Dental Materials, Ponta Grossa, PR - Brazil

\begin{abstract}
Aim: To evaluate the effect of different in-office bleaching agents on the permeability, roughness and surface microhardness of human enamel. Methods: For evaluation of roughness and microhardness, 40 hemi-faces of 20 premolars were subjected to initial roughness (Ra parameter) and microhardness (VHN) measurements. Thirty-two premolar's crowns were used for permeability test. Then, all specimens were randomly divided into four groups: $\mathrm{C}$ - without bleaching (control), HP35 - bleaching with 35\% hydrogen peroxide (HP), HPF38 - 38\% $\mathrm{HP}+$ fluoride, HPC35 - 35\% HP+calcium. Final roughness (FR) and microhardness (FM) measurements were evaluated. For permeability, the 32 crowns were immersed in $1 \%$ sodium hypochlorite (20 $\mathrm{min}$ ) and silver nitrate solutions $(2 \mathrm{~h})$ and subjected to developing solution under fluorescent light (16 h). Three sections from the crowns were analyzed in light microscope (100x) to evaluate the scores of permeability: Score 0 - no tracer agent penetration; Score 1 - less than half the thickness of enamel penetration; Score 2 - tracer agent reaching half the enamel thickness; Score 3 - entire enamel depth penetration, without reaching dentin and Score 4 - tracer agent reaching dentin. For roughness and microhardness evaluation were used one-way ANOVA and Dunnet post-test for independent samples, and $t$ test for paired samples. For permeability, the data were analyzed by Kruskal Wallis and Dunn tests. Results: A significantly higher permeability and surface roughness were observed in groups HP35, HPF38 and HPC35 compared to the C group, as well as decreased microhardness $(p<0.05)$. Conclusions: All bleaching agents increased permeability and surface roughness, and decreased microhardness of human enamel; thus, the addition of fluoride or calcium was not beneficial.
\end{abstract}

Keywords: tooth bleaching; dental enamel permeability; hydrogen peroxide; surface properties.

\section{Introduction}

Bleaching technique, either with hydrogen peroxide or carbamide peroxide,

Received for publication: September 09, 2015 Accepted: December 10, 2015

Correspondence to: Bruna Fortes Bittencourt Rua Paula Xavier, 1399 - AP 142, Centro CEP: 84010-270, Ponta Grossa, PR, Brasil Phone: +55 4232245164 - Fax: +55 4232241166

E-mail: brubita@hotmail.com has become a popular procedure, mainly due to guaranteed benefits such as the ability to promote color change and lighter shades of teeth ${ }^{1}$. The reaction mechanism of hydrogen peroxide is based on the degradation of these substances and release of reactive oxygen species, which diffuse through the enamel surface, acting primarily on dentin, breaking down high-molecular carbon rings of the chromophore molecules into smaller molecules; which, in turn, diffuse to the surface, providing the desired color change ${ }^{2}$.

There is concern that bleaching agents (hydrogen peroxide and carbamide 
peroxide) bring some damage to enamel surface, like increased roughness ${ }^{3-4}$ and permeability ${ }^{5-6}$. This effect was demonstrated in a previous study ${ }^{7}$ where silver nitrate penetration in tooth structure after bleaching was performed and it was found that these agents might diffuse into dentin by opening channels in tooth structure. Two distinct paths were observed when the silver nitrate particles penetrated through enamel and reached dentin: through the prisms and through the microcracks typical of the enamel structure ${ }^{8}$. If nitrate penetrate these channels, oxygen may penetrate more readily due to its atomic weight (seven times less than silver nitrate $)^{8}$. Probably, mineral loss may be detected after bleaching procedures ${ }^{9-10}$ and this has been pointed as the cause of microhardness decrease $\mathrm{e}^{11-12}$.

It likely that one of the causes of these adverse effects are the free oxygen radicals released during the reaction, which do not act in a specific way and may act on the organic matrix of dental structures ${ }^{13}$, breaking up the lipids and proteins of dental tissues ${ }^{14}$. Physiologically, any bleaching therapy has the ability to increase free radical levels in the pulp-dentin complex, which may induce oxidative stress in odontoblasts and tertiary dentin formation. This fact may explain the numerous reports of sensitivity observed during sessions ${ }^{15}$. Also characteristic of these changes are decreases in calcium and phosphate matrices ${ }^{9,16}$. These changes are detrimental to dental health because along with this process, there is an increased susceptibility to caries formation due to the ease of plaque adherence on the previously demineralized structure ${ }^{10,17}$.

Fluoride has proven to be effective in promoting remineralization and inhibiting enamel demineralization ${ }^{8}$. Fluoride is not the only way to ensure this remineralization, as calcium compounds also exhibit efficient recovery of lost mineral content ${ }^{18}$. With this objective, fluoride and calcium have been added to bleaching gels as alternatives to reduce these adverse effects caused by enamel bleaching ${ }^{19}$. However, controversial results are found in literature, as authors report that adding fluoride to bleaching gels shows no beneficial results in terms of reduction of enamel demineralization after bleaching ${ }^{20-21}$.

Therefore, the aim of this study was to evaluate in vitro changes in surface roughness, microhardness and permeability of human enamel when exposed to in-office bleaching agents containing fluoride or calcium in their composition. The null hypothesis tested was that bleaching agents do not influence enamel surface roughness, microhardness and permeability of the specimens.

\section{Material and methods}

The research project was approved by the Institutional Review Board - State University of Ponta Grossa: Report Number 25/2011 and Protocol Number 18741/10.

\section{Specimen preparation}

Fifty-two human premolars were used in this study. The crowns of the selected teeth were separated from their roots at the cementoenamel junction (CEJ) using a low-speed diamond saw (Isomet 1000, Buehler, Lake Bluff, IL, USA) under water cooling at $300 \mathrm{rpm}$.

Twenty crowns were used for roughness and microhardness evaluation. For permeability, 32 crowns were sealed at the CEJ with adhesive system (Adper Single Bond, 3M ESPE, St. Paul, MN, USA) and resin composite (Z100, 3M ESPE, St. Paul, MN, USA) to prevent further penetration of the tracer agent (nitrate solution; Vetec Química Fina, Xerém, RJ, Brazil) in this area.

For microhardness and roughness tests, the crowns were divided mesiodistally into two portions with a low-speed diamond saw (Isomet 1000, Buehler) at $300 \mathrm{rpm}$ under constant water cooling. Forty enamel specimens ( $2 \mathrm{~mm} \times 2$ $\mathrm{mm} \times 2 \mathrm{~mm}$ ) were obtained. Study design is displayed in Figure 1 .

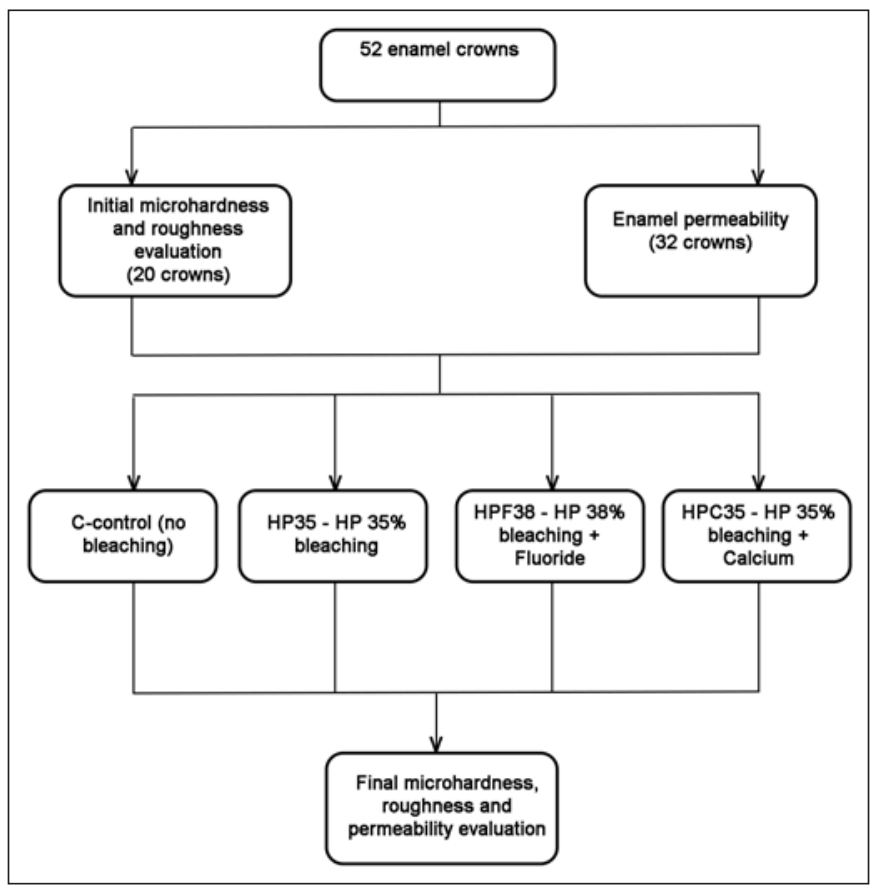

Fig. 1 - Study design flow chart.

\section{Surface roughness analysis}

After $48 \mathrm{~h}$, the initial roughness (IR) of all specimens was measured with a digital roughness meter (Mitutoyo Surftest-301; Mitutoyo-Kawasaki, Kanagawa, Japan) in all 40 specimens. The specimens were divided into four quadrants, and one measurement was made in each quadrant. From these values, the arithmetic mean was considered as the IR. The used parameters were Ra, $0.25 \mathrm{~mm}$ cutoff and $1.25 \mathrm{~mm}$ reading length.

\section{Microhardness analysis}

After the roughness analysis, the specimens were flattened with wet \#600, 1000 and 1200 grit aluminum oxide abrasive papers and polished with $6,3,1 / 2$ and $1 / 4 \mu \mathrm{m}$-grit diamond pastes in a polishing machine (Arotec, Cotia, SP, Brazil) and subjected to Vickers microhardness test (Shimadzu, Kyoto, 
Japan). The specimen's surface was divided into 4 quadrants, and 5 indentations were made with a $50 \mathrm{~g}$ load for $15 \mathrm{~s}$ each. The obtained arithmetic mean was considered as the initial microhardness (IM) of each specimen.

\section{Experimental groups - bleaching treatments}

All specimens were assigned as follows: for permeability, 32 crowns were randomly divided into 4 groups $(n=8)$, and for roughness and microhardness, 40 specimens were divided into 4 groups $(\mathrm{n}=10)$ : Group $\mathrm{C}$ - no bleaching (control); Group HP35 - bleaching with 35\% hydrogen peroxide (Whiteness HPMaxx, FGM, Joinville, SC, Brazil); Group HPF38 - bleaching with $38 \%$ hydrogen peroxide containing fluoride (Opalescence Boost PF, Ultradent, South Jordan, UT, USA) and Group HPC35 - bleaching with 35\% hydrogen peroxide containing calcium (HP Blue, FGM, Joinville, SC, Brazil). Bleaching procedures were performed according to manufacturer's instructions (Table 1). The hemi-teeth were randomized to different experimental groups in a way that specimens from the same hemi-tooth were never assigned to the same experimental group.

The control group (C) was maintained in artificial saliva and was not subjected to any bleaching treatment. All specimens were maintained in artificial saliva during all experiments.

\section{Final roughness and microhardness evaluation}

After $48 \mathrm{~h}$ of the last bleaching procedure, the specimens $(n=40)$ were subjected to final roughness $(F R)$ and final microhardness (FM) evaluations, in the same way as for the initial evaluations.

\section{Permeability analysis}

The methodology of permeability analysis was based on previous studies ${ }^{5,7,22}$. After bleaching, all specimens, including the control group $(n=32)$, were stored in a dark environment in artificial saliva for $48 \mathrm{~h}$ at $37^{\circ} \mathrm{C}$.

The lingual and proximal surfaces and the CEJ were sealed with cyanoacrylate resin (Super Bonder Loctite, Henkel Ltda, São Paulo, SP, Brazil) and a nail varnish to prevent dye penetration of silver nitrate (tracer agent) through this area. The nail varnish was also used to delimit an area of $4 \mathrm{x}$ $4 \mathrm{~mm}$ in the middle third of the labial surface. Specimens were then immersed in $50 \%$ aqueous silver nitrate solution (Vetec Química Fina, Xerém, RJ, Brazil) for $2 \mathrm{~h}$ in a dark and closed environment. Subsequently, the specimens were photodeveloped for $16 \mathrm{~h}$ (developing solution, Kodak, Eastman Kodak Company, Rochester, NY, USA). After this, the specimens were washed in tap water and the nail varnish layer was removed with manual cutting instruments.

The specimens were then embedded in a polyvinyl chloride (PVC) tube with acrylic resin (Duralay, Reliance, Dental Mfg. Co., Worth, IL, USA), and three longitudinal slices of each tooth up to approximately $0.4 \mathrm{~mm}$ thick were obtained, in a buccolingual direction, with a low-speed diamond saw (Isomet 1000, Buehler) under water cooling.

The slices were then photographed under an optical microscope (Leica ${ }^{\circledR}$, Olympus BX41-U-CA, Tokyo, Japan) with 100x magnification. The images were made with a digital camera at a 5.1 megapixels resolution. The dye penetration degree was analyzed by three previously calibrated evaluators, using a 0 to 4 score system: score 0 - no dye penetration; score 1 - less than half the enamel thickness; score 2 - half the enamel thickness; score 3 - full extent of enamel without reaching the dentin and score 4 - tracer agent reaching dentin. This evaluation was made visualizing the middle third of the dental crowns. If there was any disagreement between the evaluators, the sample under discussion was jointly analyzed until a consensus was reached. The median scores of the images from the same tooth were considered for statistical analysis using the Kruskal Wallis and Dunn tests $(\alpha=0.05)$.

\section{Statistical analysis}

Roughness and microhardness data were analyzed by one-way ANOVA and Dunnet post-test $(\alpha=0.05)$ for independent samples, and $t$ test for paired samples (initial

Table 1 - Manufacturer, application mode and composition of each material used in the study.

\begin{tabular}{lccc}
\hline Material & Manufacturer & Application mode & Composition \\
Whiteness HPMaxx & FGM, Joinville, Santa Catarina Brazil & $3-15$ min applications & $35 \%$ hydrogen peroxide, thickening agent, colorant, \\
& &
\end{tabular}

Opalescence Boost PF Ultradent Products Inc., Salt Lake City, Utah, USA

HPBlue

FGM, Joinville, Santa Catarina Brazil

Artificial saliva
3-15 min applications

One-45 min application
$38 \%$ hydrogen peroxide with $1.1 \%$ sodium fluoride and $2.6 \%$ potassium nitrate

35\% hydrogen peroxide, thickening agent, colorant, neutralizing agents, glycol calcium gluconate and deionized water 
and final values from each group). For permeability, qualitative data were analyzed by non-parametric Kruskall Wallis test and Dunn post-test $(\alpha=0.05$ and confidence interval of $95 \%$ ).

\section{Results}

Mean values and standard deviations of initial and final roughness $(\mu \mathrm{m})$ for each experimental group are in Table 2. ANOVA showed no significant differences between IR of all groups $(p=0.9312)$. For FR values, significant differences (Dunnet, $\mathrm{p}=0.0383$ ) were demonstrated between Group $\mathrm{C}$ and the other groups. The $t$ test verified that all initial values were statistically different from final values, except for Group C.

Means and standard deviations of initial and final microhardness values are in Table 3. One-way ANOVA showed no statistical differences among the initial values of all groups $(p=0.2849)$. However, the FM of Group C and Group HP35 were statistically different from HPF38 and HPC35 $(p<0.05)$, and $t$ test demonstrated significant differences between IM and FM $(p<0.05)$ for all groups except Group C.

Medians (1st/3rd interquartiles) for permeability obtained from each experimental group are in Table 4. Group $\mathrm{C}$ was statistically different from the other groups $(\mathrm{p}<0.05)$, although different medians were found in each group. The predominant score in each group is shown in Figure 2.

\section{Discussion}

The main focus of this study was to evaluate the effect of calcium and fluoride addition to bleaching agents as an alternative to reduce the adverse effects on human enamel.

Table 2 - Mean values $(\mu \mathrm{m})$ and standard deviations of initial (IR) and final roughness (FR) for each experimental group*

\begin{tabular}{lcc}
\hline GROUPS & INITIAL & FINAL \\
C & $0.31 \pm 0.08 \mathrm{Aa}$ & $0.31 \pm 0.08 \mathrm{Aa}$ \\
HP35 & $0.29 \pm 0.12 \mathrm{Aa}$ & $0.40 \pm 0.09 \mathrm{Bb}$ \\
HPF38 & $0.29 \pm 0.08 \mathrm{Aa}$ & $0.41 \pm 0.05 \mathrm{Bb}$ \\
HPC35 & $0.31 \pm 0.09 \mathrm{Aa}$ & $0.40 \pm 0.08 \mathrm{Bb}$ \\
\hline
\end{tabular}

* Lowercase letters establish relationship between columns and capital letters establish relationship between rows. Different letters show statistically significant differences $(p \leq 0.05)$

Table 3 - Mean values (VHN) and standard deviations of initial (IM) and final microhardness (FM) for each experimental group*

\begin{tabular}{lcc}
\hline GROUPS & INITIAL & FINAL \\
C & $376.1 \pm 78.6 \mathrm{Aa}$ & $370.2 \pm 78.6 \mathrm{Aa}$ \\
HP35 & $413.1 \pm 74.6 \mathrm{Aa}$ & $369.7 \pm 47.1 \mathrm{Ab}$ \\
HPF38 & $406.1 \pm 80.3 \mathrm{Aa}$ & $284.4 \pm 22.2 \mathrm{Bb}$ \\
HPC35 & $342.1 \pm 34.1 \mathrm{Aa}$ & $258.1 \pm 34.6 \mathrm{Bb}$
\end{tabular}

* Lowercase letters establish relationship between columns and capital letters establish relationship between rows. Different letters show statistically significant differences $(p \leq 0.05)$.
Table 4 - Median (1st/3rd interquartiles) for permeability degree and significance for each experimental group*

\begin{tabular}{lcc}
\hline GROUPS & $\begin{array}{c}\text { MEDIAN } \\
\text { (1st/3rd interquartiles) }\end{array}$ & SIGNIFICANCE \\
C & $1(1 / 1)$ & $\mathrm{A}$ \\
HP35 & $3(2 / 3)$ & $\mathrm{B}$ \\
HPF38 & $2(1.75 / 2.25)$ & $\mathrm{B}$ \\
HPC35 & $1.5(1 / 3)$ & $\mathrm{B}$ \\
\hline
\end{tabular}

${ }^{*}$ Different letters show statistically significant differences $(p \leq 0.05)$.

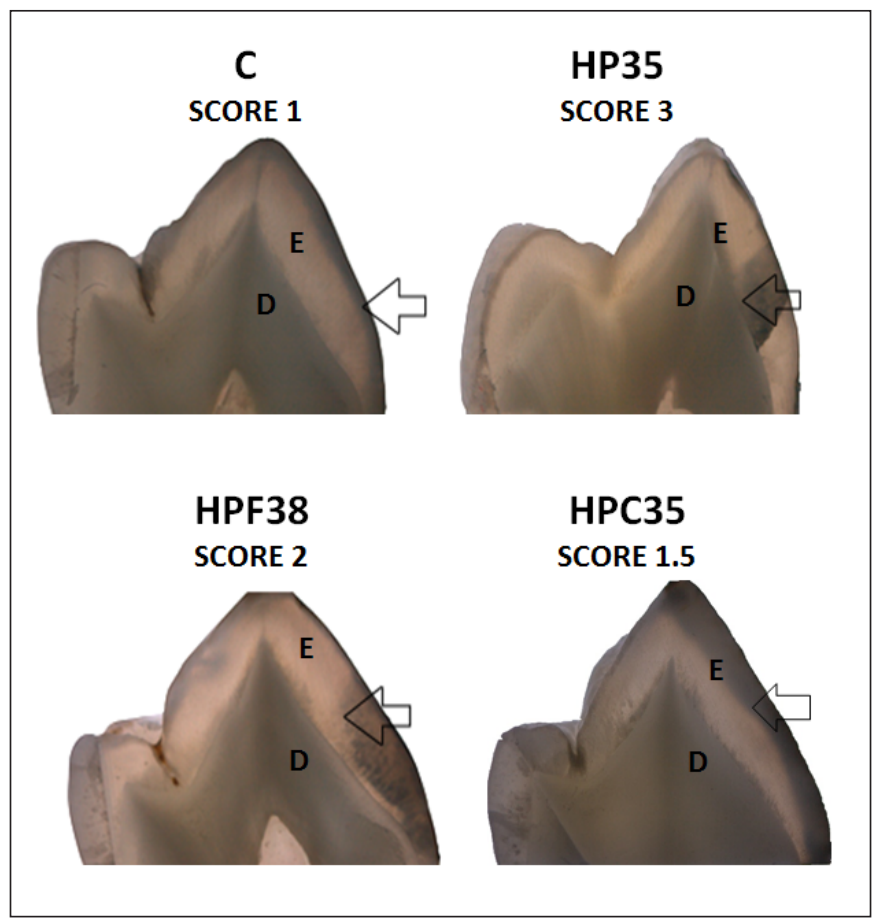

Fig. 2 - Illustrative image of the predominant score found in each group. The arrows show the dye penetration in enamel and/or dentin.

Changes in roughness, microhardness and permeability were similar, with variations occurring between bleached samples and control groups (without bleaching), regardless of calcium or fluoride content in their composition.

Similar results were found by Horning et al. ${ }^{5}$ (2013), who compared human enamel permeability after exposure to athome bleaching agent ( $6 \%$ hydrogen peroxide containing calcium) and in-office bleaching (35\% hydrogen peroxide). No significant differences between bleached groups were found, but all these groups showed a significantly increased permeability, resulting in no benefit of calcium addition to the bleaching agents. Otherwise, better results with calciumand fluoride-containing carbamide peroxide gels were found in another study ${ }^{19}$ that demonstrated that these gels promoted mineral loss minimization. One hypothesis that may explain this result is related to the lower concentrations of carbamide peroxide in relation to hydrogen peroxide used in this study.

Several factors such as concentration ${ }^{10}$, application time ${ }^{23}$ and $\mathrm{pH}^{24}$ of the bleaching agent may predict the influence of these substances on dental structures. According to Bistey et al. ${ }^{23}$ (2007), higher concentration and longer treatment result in more severe changes on human enamel. Another study ${ }^{10}$ 
showed a proportional relationship between mineral loss and bleaching agent concentration, pointing out that bleaching agents based on 35-38\% hydrogen peroxide showed significantly higher values of calcium loss compared to athome gels (10\% carbamide peroxide). The mineral loss also provides decreased microhardness values, which was found in this study and corroborated by other authors ${ }^{24}$.

The reasons for these discrepancies between the results of this study with those already published on this issue may be the above-mentioned variants. Not only the concentration and application time, but also the $\mathrm{pH}$ of the bleaching agents, may have an important role in mineral loss. A similar study ${ }^{25}$ investigated the effect of the bleaching agents' $\mathrm{pH}$ on enamel surface. There was no morphological or chemical change of the enamel surface in neutral or alkaline bleaching solutions. In the present study, care was taken to select products with similar concentrations ( 35 and $38 \%$ ), and the total time that the gels remained in contact with enamel was the same (45 min), varying only the instructions proposed by each manufacturer, as shown in Table 1. The $\mathrm{pH}$ of each bleaching gel had a slight variation (HPMaxx 6; Opalescence Boost PF 7; HPBlue 8), without significance with respect to our results.

Artificial saliva was used for specimen storage. A recent study ${ }^{26}$ demonstrated that artificial saliva is suitable to simulate the oral conditions, being closest to natural saliva. However, as this is a laboratory study; further in vivo studies are required to confirm this hypothesis, since in the oral cavity there is dentinal fluid movement coming from the pulp chamber of the tooth, which may turn enamel less permeable in the in vitro conditions ${ }^{27}$.

This study showed that all bleaching agents decreased microhardness, and increased permeability and surface roughness of human enamel; thus, the addition of fluoride or calcium was not beneficial. It is worth mentioning that clinicians should be aware of the indiscriminate use these agents, as the remineralizing compounds were not able to reverse the adverse effects in enamel tissue.

\section{References}

1. Haywood VB, Hook V, Heymann H. Nightguard vital bleaching effects of various solutions on enamel surface texture and color. Quintessence Int. 1991; 22: 775-82.

2. Dietschi D, Rossier S, Krejci I. In vitro colorometric evaluation of the efficacy of various bleaching methods and products. Quintessence Int. 2006; 37: 515-26.

3. Dominguez JA, Bittencourt B, Michel M, Sabino N, Gomes JC, Gomes OM. Ultrastructural evaluation of enamel after dental bleaching associated with fluoride. Microsc Res Tech. 2012; 75: 1093-8.

4. Markovic L, Jordan RA, Lakota N, Gaengler P. Micromorphology of enamel surface after vital tooth bleaching. J Endod. 2007; 33: 607-10.

5. Horning D, Gomes GM, Bittencourt BF, Ruiz LM, Reis A, Gomes OMM. Evaluation of human enamel permeability exposed to bleaching agents. Braz J Oral Sci. 2013; 12: 114-8.

6. Soares DGS, Ribeiro APD, Sacono NT, Coldebella CR, Hebling J, Souza Costa CA. Transenamel and transdentinal cytotoxicity of carbamide peroxide bleaching gels on odontoblast-like MDPC-23 cells. Int Endod J. 2011; 44: 116-25.
7. Mendonça LC, Naves LZ, Garcia LFR, Correr-Sobrinho L, Soares CJ, Quagliatto PS. Permeability, roughness and topography of enamel after bleaching: tracking channels of penetration with silver nitrate. Braz J Oral Sci. 2011; 10: 1-6.

8. Ten Cate JM, Buijs MJ, Miller CC, Exterkate RAM. Elevated fluoride products enhance remineralization of enamel. J Dent Res. 2008; 87: 943-7.

9. Soares DG, Ribeiro AP, Sacono NT, Loguércio AD, Hebling J, Costa CA. Mineral loss and morphological changes in dental enamel induced by a 16\% carbamide peroxide bleaching gel. Braz Dent J. 2013; 24: 517-21.

10. Al-Salehi SK, Wood DJ, Hatton PV. The effect of $24 \mathrm{~h}$ non-stop hydrogen peroxide concentration on bovine enamel and dentine mineral content and microhardness. J Dent. 2007; 35: 845-50

11. Klaric E, Rakic M, Sever I, Milat O, Par M, Tarle Z. Enamel and dentin microhardness and chemical composition after experimental light-activated bleaching. Oper Dent. 2015; 40: E132-41.

12. Magalhães JG, Marimoto AR, Torres CR, Pagani C, Teixeira SC, Barcellos DC. Microhardness change of enamel due to bleaching with in-office bleaching gels of different acidity. Acta Odontol Scand. 2012; 70: 122-6.

13. Hegedüs C, Bistey T, Flora-Nagy E, Keszthelyi G, Jenei A. An atomic force microscopy study on the effect of bleaching agents on enamel surface. J Dent. 1999; 27: 509-15.

14. Minoux M, Serfaty R. Vital tooth bleaching: biologic adverse effects - a review. Quintessence Int. 2008; 39: 645-59.

15. Leonard RH Jr, Haywood VB, Phillips C. Risk factors for developing tooth sensitivity and gingival irritation associated with Nightguard vital bleaching. Quintessence Int. 1997; 28: 527-34.

16. Soares DG, Ribeiro AP, Sacono NT, Loguércio AD, Hebling J, Costa CA. Mineral loss and morphological changes in dental enamel induced by a 16\% carbamide peroxide bleaching gel. Braz Dent J. 2013; 24: 517-21.

17. Hosoya N, Honda K, lino F, Arai T. Changes in enamel surface roughness and adhesion of Streptococcus mutans to enamel after vital bleaching. J Dent. 2003; 31: 543-8.

18. Langhorst SE, O'Donnell JN, Skrtic D. In vitro remineralization of enamel by polymeric amorphous calcium phosphate composite: quantitative microradiographic study. Dent Mater. 2009; 25: 884-91.

19. Cavalli V, Rodrigues LKA, Paes-Leme AF, Soares LES, Martin AA, Berger SB, et al. Effects of the addition of fluoride and calcium to lowconcentrated carbamide peroxide agents on the enamel surface and subsurface. Photomed Laser Surg. 2011; 29: 319-25.

20. Attin T, Kocabiyik M, Buchalla W, Hannig C, Becker K. Susceptibility of enamel surfaces to demineralization after application of fluoridated carbamide peroxide gels. Caries Res. 2003; 37: 93-9.

21. Tschoppe P, Neumann K, Mueller J, Kielbassa AM. Effect of fluoridated bleaching gels on the remineralization of predemineralized bovine enamel in vitro. J Dent. 2009; 37: 156-62.

22. Muñoz MA, Luque I, Hass V, Reis A, Loguercio AD, Bombarda NHC. Immediate bonding properties of universal adhesives to dentine. J Dent. 2013; 41: 404-11.

23. Bistey T, Nagy IP, Simó A, Hegedus C. In vitro FT-IR study of the effects of hydrogen peroxide on superficial tooth enamel. J Dent. 2007; 35: 32530.

24. Lia Mondelli RF, Garrido Gabriel TR, Piola Rizzante FA, Magalhães AC, Soares Bombonatti JF, Ishikiriama SK. Do different bleaching protocols affect the enamel microhardness? Eur J Dent. 2015; 9: 25-30.

25. Xu B, Li Q, Wang Y. Effects of $\mathrm{pH}$ values of hydrogen peroxide bleaching agents on enamel surface properties. Oper Dent. 2011; 36: 554-62.

26. Zeczkowski M, Tenuta LM, Ambrosano GM, Aguiar FH, Lima DA. Effect of different storage conditions on the physical properties of bleached enamel: An in vitro vs. in situ study. J Dent. 2015; 43: 1154-61.

27. Vongsavan N, Matthews $B$. The permeability of cat dentin in vivo and in vitro. Arch Oral Biol. 1991; 36: 641-6. 